\title{
Evaluation of Genetic Variability, Heritability and Genetic Advance for Yield and Yield Components in Rice Genotypes
}

\author{
Sriram Ajmera ${ }^{1}$, S. Sudheer Kumar ${ }^{2}$ and V. Ravindrababu ${ }^{3}$ \\ ${ }^{1}$ Department of Genetics and Plantbreeding, College of Agriculture, PJTSAU, \\ Rajendranagar, Hyderabad, Telangana, India \\ ${ }^{2}$ PJTSAU, Rajendranagar, Hyderabad, Telangana, India \\ ${ }^{3}$ Indian Institute of Rice Research, Rajendranagar, Hyderabad, Telangana, India \\ *Corresponding author
}

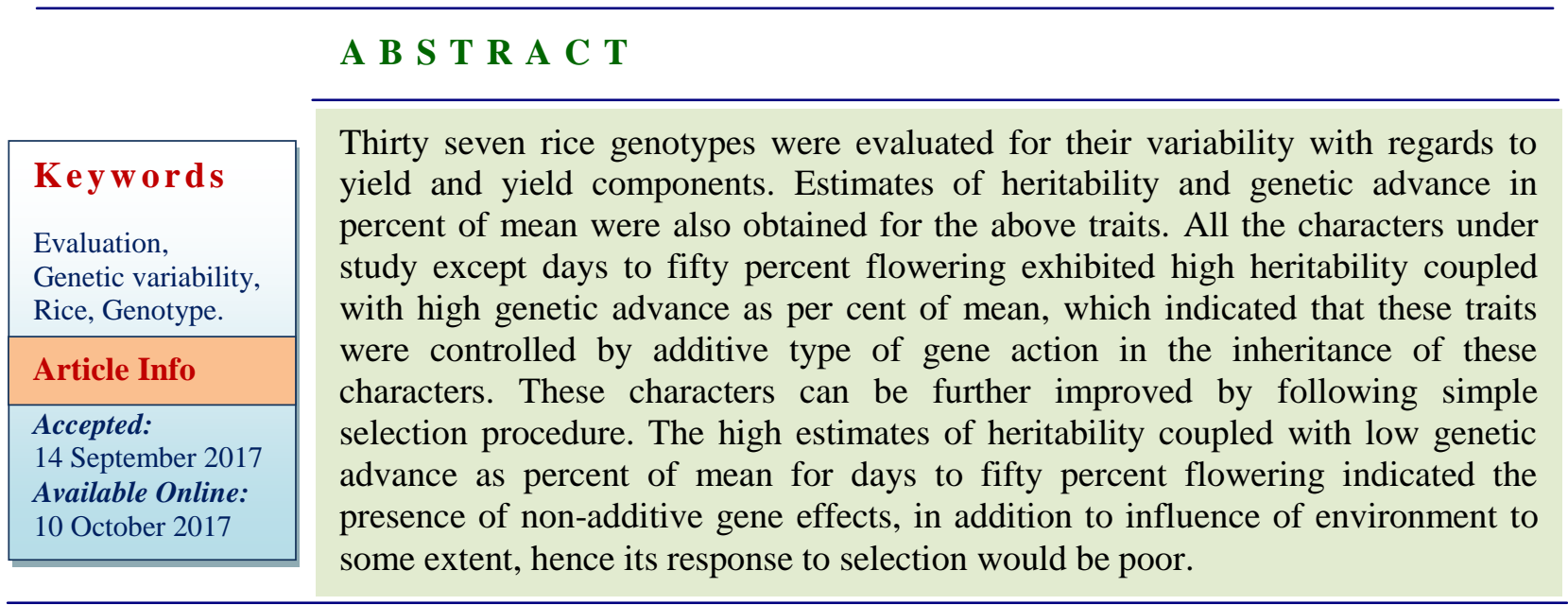

\section{Introduction}

Rice (Oryza sativa L.) is the primary staple food for one third of the world population after maize and wheat and has been referred to as "Global Grain" (Shalini and Tulasi, 2008). It is considered a model cereal crop in the world due to its relatively small genome size, vast germplasm collection, enormous repertoire of molecular genetic resources and efficient transformation system (Paterson et al., 2005).

In India, rice is cultivated in an area of nearly 43.85 million hectares with an annual production of 104.78 million tones and productivity of $2185 \mathrm{~kg} \mathrm{ha}^{-1}$, while in Telangana rice is grown in an area of 2.29 million hectares with an annual production and productivity of 6.62 million tonnes and $1334 \mathrm{~kg} \mathrm{ha}^{-1}$, respectively (Indiastat, 2014$15)$.

In Indian agriculture, rice plays a pivotal role, being the livelihood for 150 million rural households and accounting for $43 \%$ of National food grain production (IIRR, 2005). The area planted with rice in major production countries has been decreasing because of industrialization and urbanization. 
Hence, increasing rice yields on existing land remains the primary strategy for increasing production, to meet the future demand for food, anticipated from the projected world population increase. To produce 176 million tons additional rice by 2035, the yield potential of rice needs to be increased from 10 to 12.3 tons per hectare (Khush, 2013).

Before initiating any breeding programme, the knowledge of variability and genetic diversity is a basic pre-requisite for improving the character. Similarly the additional information regarding the genetic parameters like genotypic coefficient of variation and expected genetic advance as percent of mean helps in selecting a proper breeding methodology for genetic improvement of the trait.

The success of plant breeding depends on the extent of genetic variability present in a crop. Knowledge on the nature and magnitude of genetic variation governing the inheritance of quantitative characters like yield and its components is essential for genetic improvement. A critical analysis of genetic variability present in the germplasm of a crop and its estimation is a pre-requisite for initiating any crop improvement programme as well as adopting appropriate selection techniques.

It is very difficult to judge whether observed variability is heritable or not. Heritability indicates the extent of transmissibility of a character into future generations. Moreover, knowledge of heritability is also essential for selection of component traits for yield improvement. Genetic advance measures the difference between the mean genotypic values of selected population and the original population from which these were selected. Heritability estimates along with genetic advance is normally more helpful in predicting the genetic gain under selection than heritability estimates alone.
Heritability is the ratio of genotypic variance to total or phenotypic variance (Broad sense) and the ratio of additive genetic variance to phenotypic variance (Narrow sense). Genetic advance is the improvement in mean genotypic value of selected plants over the parental population.

Identification of effective selection criteria for effective yield improvement. The present investigation was under taken in this context to elucidate information on variability, heritability and genetic advance in rice genotypes.

\section{Materials and Methods}

The experiment was conducted at RARS JAGTIAL, Telangana, India, during kharif 2013-14 season. The experimental material comprised of 37 rice genotypes. The experiment was laid out in a Randomized Block Design (RBD) with three replications. The nursery was sown in raised beds and healthy nursery was raised at all the locations following uniform package of practices. Thirty days old seedlings were transplanted following a spacing of $20 \times 15 \mathrm{~cm}$ with a row length of $4.5 \mathrm{~m}$ for each entry.

The packages of practices as recommended by ANGRAU were adopted as per schedule throughout the crop growth period with need based plant protection measures. Fertilizers were applied at the rate of $120 \mathrm{~kg}$ Nitrogen, $60 \mathrm{~kg}$ Phosphorus and $40 \mathrm{~kg}$ potash ha ${ }^{-1}$.

Nitrogen was applied 3 times by broadcasting at transplanting; tillering stage and panicle initiation, phosphorous and potash were applied as basal at the time of transplanting by broadcasting method. Necessary precautions were taken to maintain the crop very well. Data on days to $50 \%$ flowering (DFF), days to maturity (DM) recorded at respective stage of crop while, plant height $(\mathrm{PH})$, panicle length (PL), productive tillers 
per plant $(\mathrm{PT})$ were recorded at harvest and number of grains per panicle (GPP), testweight (TW), grain iron content $(\mathrm{Fe})$, grain zinc content $(\mathrm{Zn})$ and grain yield per plant (GY) recorded after harvest.

Estimation of iron and zinc Iron and zinc content of grain samples were estimated by Atomic Absorption Spectrophotometer [3]. One gram of seed was taken and powdered it in the grinder (nonmetallic grinder).

Powdered seed sample was digested in triacids $(\mathrm{HNO} 3+\mathrm{HCl} 4+\mathrm{H} 2 \mathrm{SO} 4)$ mixture (10:4:1) in micro-oven digester. The digested sample was cooled for 30 minutes and the volume was made up to $50 \mathrm{ml}$ with double distilled water.

Then a known quantity of aliquot was used for subsequent analysis. A suitable blank was run simultaneously to account for the contamination from the reagents. Zinc and Iron content were estimated in the aliquot of seed extract by using Atomic Absorption Spectrophotometer (AAS) at $213.86 \mathrm{~nm}$ for zinc and $248.33 \mathrm{~nm}$ for iron.

Statistical methods for calculating the variance, heritability and genetic advance are below discussed

\section{Variance}

The genotypic and phenotypic variance was calculated as per the formulae (Burton and Devane, 1953).

(Mean sum of squares due to treatments Mean sum of squares due to error) Genotypic variance $\left(\sigma_{\mathrm{g}}^{2}\right)=$

Number of replications

Phenotypic variance $\left(\sigma_{\mathrm{p}}^{2}\right)=\left(\sigma_{\mathrm{g}}^{2}\right)+\left(\sigma_{\mathrm{e}}^{2}\right)$

$\left(\sigma^{2}\right)=$ Error variance
Genotypic and phenotypic coefficients of variance

The genotypic and phenotypic coefficients of variation were calculated according to the formula given by falconer (1981).

Genotypic

Genotypic standard deviation

Coefficient of variation $=$

Mean $\times 100$

Phenotypic

Phenotypic standard deviation

Coefficient of variation $=$ $\times 100$

Mean

Categorization of the range of variation was effected as proposed by Sivasubramanian and Madhavamenon (1973).

$<10 \%$ : low

10-20\%: moderate

$>20 \%$ : high

\section{Heritability and genetic advance}

\section{Heritability}

Heritability in the broad sense refers to the proportion of genotypic variance to the total observed variance in the total population. Heritability $\left(h^{2}\right)$ in the broad sense was calculated according to the formula given by Allard (1960).

$h^{2}=\begin{gathered}\sigma_{g}^{2} \\ \sigma_{p}^{2}\end{gathered}$

Where

$\mathrm{h}^{2}=$ heritability in broad sense

$\sigma^{2} \mathrm{~g}=$ genotypic variance

$\sigma_{\mathrm{p}}^{2}=$ phenotypic variance $\left(\sigma_{\mathrm{g}}^{2}\right)+\left(\sigma_{\mathrm{e}}^{2}\right)$

$\sigma^{2}{ }_{\mathrm{e}}=$ environmental variance 
As suggested by Johnson et al., (1955) $\left(\mathrm{h}^{2}\right)$ estimates were categorized as:

Low: 0-30\%

Medium: 30-60\%

High: above $60 \%$

\section{Genetic advance}

Genetic advance refers to the expected gain or improvement in the next generation by selecting superior individuals under certain amount of selection pressure. From the heritability estimates the genetic advance was estimated by the following formula given by Burton (1952).

$\mathrm{GA}=\mathrm{K} \cdot \mathrm{h}^{2}(\mathrm{~b}) \cdot \sigma_{\mathrm{p}}$

Where

$\mathrm{GA}=$ expected genetic advance

$\mathrm{K}=$ Selection differential, the value of which is 2.06 at $5 \%$ selection intensity

$\sigma_{\mathrm{p}}=$ phenotypic standard deviation

$\mathrm{h}^{2}(\mathrm{~b})=$ heritability in broad sense

In order to visualize the relative utility of genetic advance among the characters, genetic advance as percent for mean was computed.

Genetic advance

As percent of mean $=---------------\times 100$

Grand mean

The range of genetic advance as percent of mean was classified as suggested by Johnson et al., (1955).

Low: less than $10 \%$

Moderate: 10-20\%

High: more than $20 \%$

\section{Results and Discussion}

The results obtained from the present experimental study on evaluation of 50 rice genotypes are furnished under the Genetic variability, Heritability and genetic advance.

Genetic variability, heritability and genetic advance

The genotypic and phenotypic coefficients of variation, heritability and genetic advance as per cent of mean were estimated for 37 genotypes. Results are furnished in Table 1 for PCV, GCV and heritability, genetic advance as per cent of mean respectively.

The characters studied in the present investigation exhibited low, moderate and high PCV and GCV values.

\section{Days to 50 per cent flowering}

The genotypic and phenotypic coefficients of variation were low i.e., 10.84 and 11.312, respectively. The observed heritability estimate for this trait was high (91.9) while genetic advance as per cent of mean (21.42) were moderate. The results were conformity with Sameera et al., (2015) for moderate GCV and PCV and Gampala et al., (2015) for high heritability and Islam et al., (2015) for moderate genetic advance as percent of mean.

\section{Plant height (cm)}

The genotypic and phenotypic coefficients of variation for this trait were moderate i.e., 19.12 and 19.41 respectively. The observed heritability estimate was high (97.0) and with high genetic advance as per cent of mean (38.81). The similar results were reported by Dhanwani et al., (2013) for high GCV and PCV and Sameera et al., (2015) reported high heritability coupled with high genetic advance as per cent of mean for plant height in rice. 


\section{Panicle length $(\mathrm{cm})$}

The genotypic and phenotypic coefficients of variation for this trait were moderate i.e., 10.59 and 11.09 respectively.

The observed heritability estimate was high (91.1) and with moderate genetic advance as per cent of mean (20.82). The similar results were reported by Dhanwani et al., (2013) for moderate GCV and PCV and Sameera et al., (2015) reported high heritability coupled with high genetic advance as per cent of mean for panicle length per plant in rice.

\section{Number of productive tillers per plant}

The genotypic and phenotypic coefficients of variation for this trait were high i.e., 21.88 and 22.13 respectively. The observed heritability estimate was high (97.8) and with high genetic advance as per cent of mean (44.58). The similar results were reported by Allam et al., (2015) for high PCV and Karande et al., (2015) reported high heritability coupled with high genetic advance as per cent of mean for number of productive tillers per plant in rice.

\section{Number of grains per panicle}

A high GCV (29.10) and PCV (29.19) were observed for this trait. The heritability estimate for this trait was very high (98.7) with high genetic advance as per cent of mean (59.57). The similar results were observed by Mohan et al., (2015) and Sameera et al., (2015)for high GCV and PCV, Karande et al., (2015) for high heritability and for high genetic advance as percent of mean.

\section{Number of filled grains per panicle}

A high GCV (30.68) and PCV (30.85) were observed for this trait. The heritability estimate for this trait was very high (98.9) with high genetic advance as per cent of mean (62.84).The similar results were observed by Mohan et al., (2015) and Sameera et al., (2015)for high GCV and PCV, Karande et al., (2015) for high heritability and for high genetic advance as percent of mean.

Table.1 Estimates of variability, heritability and genetic advance in rice genotypes

\begin{tabular}{|l|c|c|c|c|}
\hline \multicolumn{1}{|c|}{ Characters } & PCV (\%) & GCV (\%) & $\begin{array}{c}\text { Heritability in broad } \\
\text { sense(h } \mathbf{h}^{\mathbf{2}} \text { \% }\end{array}$ & $\begin{array}{c}\text { Gen. Adv as per cent of Mean } \\
(\mathbf{a t ~ 5 \% )}\end{array}$ \\
\hline Days to 50\% Flowering & 11.31 & 10.84 & 0.919 & 21.44 \\
\hline Plant height & 19.41 & 19.12 & 0.970 & 38.81 \\
\hline Panicle length & 11.09 & 10.59 & 0.911 & 20.82 \\
\hline Productive tillers per hill & 22.13 & 21.88 & 0.978 & 44.58 \\
\hline No. of grains per panicle & 29.29 & 29.10 & 0.987 & 59.57 \\
\hline $\begin{array}{l}\text { No. of filled grains per } \\
\text { panicle }\end{array}$ & 30.85 & 30.68 & 0.989 & 62.84 \\
\hline 1000 grain weight & 16.37 & 16.03 & 0.959 & 32.35 \\
\hline Grain yield per plant & 41.86 & 41.72 & 0.993 & 85.61 \\
\hline Grain iron content & 17.18 & 16.85 & 0.963 & 34.07 \\
\hline Grain zinc content & 21.97 & 21.73 & 0.973 & 44.27 \\
\hline
\end{tabular}




\section{0-grain weight (g)}

Moderate GCV (16.03) and PCV (16.37) were recorded with high heritability estimate of (95.9) and the genetic advance as per cent of mean was high (32.35). The similar results were found by Suresh et al., (2014) and Shekawat et al., (2015) for moderate GCV and PCV and Gampala et al., (2015) and Islam et al., (2015) for high heritability coupled with high genetic advance as percent of mean.

\section{Grain per Plant (g)}

A high genotypic coefficient of variation (41.72) and phenotypic coefficient of variation (41.86) were observed for this trait. A high heritability estimate (99.3) coupled with high genetic advance as per cent of mean (85.61). The results were conformity with Allam et al., (2015) and Bhati et al., (2015) for high GCV and PCV and Rahman et al., (2014) and Karande et al., (2015) for high heritability coupled with high genetic advance as percent of mean.

\section{Grain iron concentration (mg/kg)}

The genotypic and phenotypic coefficients of variation were medium i.e., 16.85 and 17.18, respectively. The observed heritability estimate for this trait was high (96.3) while genetic advance as per cent of mean (34.07) were high. The result is conformity with Gangashetty et al., (2013) for medium GCV and PCV and Sala et al., (2015) for high heritability coupled with high genetic advance as percent of mean.

\section{Grain zinc concentration (mg/kg)}

The genotypic and phenotypic coefficients of variation were high i.e., 21.74 and 21.97, respectively. The observed heritability estimate for this trait was high (96.0) while genetic advance as per cent of mean (45.98) were high. The result is conformity with Bekele et al., (2013) for high GCV and PCV and Sala et al., (2015) for high heritability coupled with high genetic advance as percent of mean.

The knowledge of genetic variability present in a given crop species for the character under improvement is of paramount importance for the success of any plant breeding programme. Information on coefficient of variation is useful in measuring the range of variability present in the characters. Heritability and genetic advance are important selection parameters. Genotypic coefficient of variation (GCV) along with heritable estimates would provide a better picture of the amount of genetic advance to be expected by phenotypic selection (Burton, 1952). It is suggested that genetic gain should be considered in conjunction with heritability estimates (Johnson et al., 1955). Heritability estimates along with genetic advance are normally more helpful in predicting the gain under selection than heritability estimates alone.

Coefficients of variation studies indicated that the estimates of PCV were slightly higher than the corresponding GCV estimates for days to $50 \%$ flowering, plant height, panicle length, number of productive tillers per plant, number of grains per panicle, number of filled grains per panicle, 1000 grain weight, grain yield per plant, grain iron concentration and zinc concentration indicating that the characters were less influenced by the environment. Therefore, selection on the basis of phenotype alone can be effective for the improvement of these traits.

The estimates of heritability act as predictive instrument in expressing the reliability of phenotypic value. Therefore, high heritability helps in effective selection for a particular character. 
High heritability for quantitative characters indicates the scope of genetic improvement of these characters through selection, which revealed that these characters are less influenced by environment and there could be greater correspondence between phenotypic and breeding values.

The genetic advance as percent of mean is a useful indicator of the progress that can be expected as a result of exercising selection on the pertinent population. The traits which are recorded showed high heritability coupled with high genetic advance. It indicates the control of additive gene and selection may be effective for these characters.

\section{References}

Allam, C.R., Jaiswal, H.K., Qamar, A., Venkateshwarlu, $\mathrm{C}$ and Reddy, Y.S. 2015. Variability, heritability and genetic advance studies in some indigenous genotypes of basmati rice (Oryza sativa L.). Electronic Journal of Plant Breeding.6(2): 506-511.

Allard, R.W., 1960. Principles of Plant Breeding.Publishers by John Wiley and Sons Inc., New York, USA. 485.

Bekele, B.D., Rakhi, S., Naveen, G. K., Kundur, P.J and Shashidar, H.E. 2013. Estimation of genetic variability and correlation studies for grain zinc concentrations and yield related traits in selected rice (Oryza sativa L.) genotypes. Asian Journal of Experimental Biology. 4(3): 391-397.

Bhati, M., Sureshbabu, G., Aishwarya, S.R. 2015. Genetic variability, correlation and path coefficient for grain yield and quantitative traits of elite rice (Oryza sativa L.) genotypes at Uttar Pradesh. Electronic Journal of Plant Breeding. 6(2): 586-591.

Burton, G. W., 1952. Quantitative inheritance in grasses. Proceeding on $6^{\text {th }}$
International Grassland Congress Journal. 1: 277-283.

Dhawani, R.K., Sarawgi, A.K., Solanki, A and Tiwari, J.K. 2013. Genetic variability analysis for various yield attributing and quality traits in rice (Oryza sativa L.). The Bioscan. 8(4): 1403-1407.

DRR, 2005. Annual Progress Report 2005. Directorate of Rice Research, Rajendranagar, Hyderabad, 3: 133-135.

Falconer, D. S., 1964. Introduction to quantitative genetics. Longmann. pp. 294-300.

Gampala, S., Singh, V.K and Chakraborti, K. 2015. Analysis of variability and genetic parameter for grain quality attributes in high yielding rice (Oryza Sativa L.) genotypes. The EcoScan. 9(1\&2): 411-414.

Gangashetty, P.I., Salimath, P.M and Hanamaratti, N.G. 2013. Genetic Variability studies in genetically diverse non-basmati local aromatic genotype of rice (Oryza sativa L). Rice Genomics and Genetics. 4(2): 4-8.

Indiastat. 2014-15. Area, production and productivity of rice in India and Telangana. http://www.indiastat.com.

Islam, M.A., Hasan, A.K., Raffi, S.A and Hossain, M.A. 2015. Analysis of genetic variability, heritability and genetic advance for yield and yield associated traits in some promising advanced lines of rice. Progressive Agriculture.26: 26-31.

Johnson, H.W., Robinson, H.F and Comstock, R.E. 1955. Estimates of genetic and environmental variability in soybean. Agronomy Journal. 47 (7): 314-318.

Karande, S.S., Thaware, B.L., Bhave, S.G and Burondkar, M.M. 2015. Estimate of genetic variability and heritability in some exotic germplasm lines in kharif rice (Oryza Sativa L.). International Journal of Applied Biology and 
Pharmaceutical Technology. 6(4):128130.

Khush, G.S., 2013. Strategies for increasing the yield potential of cereals: case of rice as an example. Plant Breeding. 132: 433-436.

Mohan Lal, and Devendra, K. Chauhan. 2011. Studies of genetic variability, heritability and genetic advance in relation to yield traits in rice. Agricultural Science Digest. 31(3): 220 $-222$.

Mohan, Y.C., Thippeswamy, S., Bhoomeshwar, K., Madhavilatha, B and Jameemasamreen. 2015. Diversity analysis for yield and gall midge resistance in rice (Oryza sativa 1.) in Northern Telangana zone, India. Journal of breeding and genetics 47(2): 160171.

Paterson, A.H., Freeling, $\mathrm{M}$ and Sasaki, T. 2005. Grains of knowledge: genomics of model cereals. Genome Research. 15: 1643-1650.

Rahman, M.A., Hossain, M.S., Chowdary, I.F., Matin, M.A and Mehraj, H. 2014. Variability study of advanced fine rice with correlation, path co- efficient analysis of yield contributing characters. International Journal of Applied Science and Biotechnology. 2(3): 364-370.

Sala, M., Anandakumar, C.R and Geetha. 2015. Variability studies for quality traits in rice with high iron and zinc content in segregating population. Journal of Cereals and Oilseeds. 6(7): $39-42$.

Sameera, S.K., Prasannarajesh, A., Jayalakshmi, V., Nirmala, P.J and Srinivas, T. 2015. Genetic variability studies for yield and yield components in rice (Oryza sativa L.). Electronic Journal of Plant Breeding.6 (1): 269273.

Shalini, P., and Tulsi, T. 2008. Production potential and nutrient use efficiency of basmati rice (Oryza sativa L.) under integrated nutrient management. Green Farming. 1(9): 11-13.

Shekhawat, R., Harsh, V.S., Singh, R.P and Yashpal. 2015. Studies on variability, heritability and genetic advance in rice (Oryza sativa L.) germplasm lines. Annals of Agri- Bio Research.20 (1): 22-25.

Sivasubramanian, S., and Madhavamenon, P. 1973. Combing ability in rice. Madras Agricultural Journal. 60: 419-421.

Suresh, K., Shivakumar, N., Kiran, K.K., Krishnappa, M and Somu, G. 2014. Genetic variability and heritability studies for grain yield and yield attributes in diverse rice (Oryza sativa L.). Inbred lines. Trends in Biosciences. 7 (10): 958-960.

\section{How to cite this article:}

Sriram Ajmera, S. Sudheer Kumar and Ravindrababu, V. 2017. Evaluation of Genetic Variability, Heritability and Genetic Advance for Yield and Yield Components in Rice Genotypes. Int.J.Curr.Microbiol.App.Sci. 6(10): 1657-1664. doi: https://doi.org/10.20546/ijcmas.2017.610.200 